\title{
Balloon dilatation (valvoplasty) as first line treatment for severe stenosis of the aortic valve in early infancy: medium term results and determinants of survival
}

Department of Paediatric Cardiology, Bristol Royal Hospital for Sick Children, Bristol

F A Bu'Lock

H S Joffe

$S$ C Jordan

R P Martin

Correspondence to: Dr Frances Bu'Lock, Heart Unit, Birmingham Children's Hospital, Ladywood Middleway, Ladywood, Birmingham B16 8ET.

Accepted for publication 14 June 1993

Frances A Bu'Lock, Hyam S Joffe, Stephen C Jordan, Robin P Martin

\begin{abstract}
Objective-To assess the results of balloon dilatation of the aortic valve as first line treatment for infants presenting in the first two months of life with cardiac failure caused by severe aortic stenosis. Design-A prospective study of all such infants presenting to a single centre over a three year period.

Patients-Of 14 consecutive infants aged $<2$ months presenting with heart failure due to severe stenosis of the aortic valve, 12 underwent balloon dilatation of the valve. Two infants with hypoplastic left heart syndrome were excluded. Six patients had other significant cardiac malformations, nine had endocardial fibroelastosis. Four infants were moribund at presentation.

Interventions-Balloon dilatation was performed through the femoral artery under general anaesthetic, with heparin and antibiotic prophylaxis. Maximum inflated balloon size was selected as equal to or slightly less than the diameter of the aortic valve measured echocardiographically. In two infants balloon dilatation of coexistent severe coarctation was performed at the same time.
\end{abstract}

Results-Dilatation was achieved in all cases. Early survival rate (up to one month) was $75 \% ; 50 \%$ survive up to three years. The two deaths occurring $<24$ hours after dilatation probably related to the infants' poor condition at presentation and the presence of significant left ventricular hypoplasia. The other early death was due to severe mitral regurgitation from papillary muscle dysfunction. All later deaths were related to associated malformations. The difference in left ventricular size (diameter and length) measured echocardiographically at presentation between survivors and those that died is significant $(p \leqslant 0.002)$. $83 \%$ of deaths occurred in infants with associated malformations. Cusp perforation occurred in one infant, which may have contributed to this patient's death. Left ventricular perforation and cardiac tamponade were treated successfully by prompt pericardiocentesis in another. Conclusions-Balloon dilatation of the aortic valve is an acceptable first line treatment for neonates with severe symptomatic stenosis of the aortic valve. Outcome depends principally on left ventricular size and on the presence, severity, and timing of treatment of associated malformations. Severe endocardial fibroelastosis was not a risk factor for early death but may have implications for long term survival. The survival rate for this high risk group might be improved by a stratified approach where patients with adequate left ventricular size have balloon dilatation whereas those with severe ventricular hypoplasia are managed like patients with the hypoplastic left heart syndrome.

(Br Heart f 1993;70:546-553)

Patients with severe stenosis of the aortic valve presenting with heart failure in the neonatal period have historically been associated with a very poor outcome, even with prompt treatment. Only $16 \%$ of 22 infants born with severe or critical aortic stenosis in the Liverpool area between 1960 and 1990 survived more than three years after presentation. ${ }^{1}$

Balloon dilatation of the valve is now accepted as an effective palliative treatment, with a low complication rate, for the treatment of congenital stenosis of the aortic valve in older children. ${ }^{2-4}$ The application of this technique to the neonate and very young infant is more controversial. It is known that surgical treatment in this age group has been associated with a high mortality, ${ }^{56}$ although better surgical results have been reported by some centres. ${ }^{78}$ Improvements in balloon and catheter design over the past few years have facilitated balloon dilatation in this age group. ${ }^{9}$ Early reports have shown favourable results $^{1011}$ but comparison with surgical series is hampered by wide variation in patient selection. Thus a prospective assessment of the results of balloon dilatation rather than surgical valvotomy as first line treatment is indicated, with particular attention to factors known to influence mortality in surgical series, such as the degree of left ventricular hypoplasia. Medium term results from a single unit are presented.

\section{Patients and methods}

STUDY GROUP

Table 1 shows the clinical details. Since May 1989,12 out of the 14 infants who consecutively presented to our unit with cardiac failure due to severe stenosis of the aortic valve within the first two months of life have under- 
Table 1 Clinical details

\begin{tabular}{|c|c|c|c|c|c|c|c|}
\hline $\begin{array}{l}\text { Patient } \\
\text { No }\end{array}$ & $\begin{array}{l}\text { Age at } \\
\text { presentation } \\
\text { (days) }\end{array}$ & $\begin{array}{l}\text { Clinical } \\
\text { state }\end{array}$ & $\begin{array}{l}\text { Age at } \\
\text { dilatation } \\
\text { (days) }\end{array}$ & $\begin{array}{l}\text { Weight at } \\
\text { presentation } \\
(\mathrm{kg})\end{array}$ & $E F E$ & $\begin{array}{l}\text { Associated } \\
\text { abnormalities }\end{array}$ & Outcome \\
\hline 1 & 4 & $\begin{array}{l}\text { Acidosis, CCF } \\
\text { ventilated, } \\
\text { inotropes, } P, D O\end{array}$ & 5 & 3.5 & Severe & - & $A$ and $W$ \\
\hline $\begin{array}{l}2 \\
3\end{array}$ & $\begin{array}{l}2 \\
4\end{array}$ & $\begin{array}{l}\text { CCF, DO } \\
\text { CCF, DO }\end{array}$ & $\begin{array}{l}7 \\
5\end{array}$ & $\begin{array}{l}3 \cdot 3 \\
3 \cdot 25\end{array}$ & $\begin{array}{l}\text { Severe } \\
\text { Severe }\end{array}$ & Late coarct & $\begin{array}{l}\text { D } 10 / 12 \\
\text { A diur }\end{array}$ \\
\hline 4 & 3 & CCF & 55 & 3.9 & Mild & $\begin{array}{l}\text { Severe coarct } \\
\text { (Operated 6/7) }\end{array}$ & $A$ and $W$ \\
\hline 5 & 2 & $\mathrm{CCF}, \mathrm{P}, \mathrm{DO}$ & 3 & $3 \cdot 25$ & Mild & $\begin{array}{l}\text { AVSD, } \\
\text { Mild coarct }\end{array}$ & D $2 / 12$ \\
\hline 6 & 13 & $\begin{array}{l}\text { Acidosis, } \mathrm{CCF} \text {, } \\
\text { ventilated } \\
\text { inotropes, } \mathrm{P}, \mathrm{DO}\end{array}$ & 15 & $3 \cdot 1$ & - & Severe MR & D $2 / 52$ \\
\hline 7 & 42 & CCF & 46 & $4 \cdot 6$ & Moderate & - & $A$ and $W$ \\
\hline 8 & 6 & $\begin{array}{l}\text { Acidosis, CCF, } \\
\text { ventilated, } \\
\text { inotropes, P, DO }\end{array}$ & 8 & $3 \cdot 2$ & Moderate & $\begin{array}{l}\text { Severe coarct } \\
\text { Small VSD }\end{array}$ & $\mathrm{D}<24 \mathrm{hr}$ \\
\hline 9 & 1 & $\mathrm{CCF}, \mathrm{DO}$ & 2 & $3 \cdot 2$ & - & $\begin{array}{l}\text { Severe coarct } \\
\text { Turner's syndrome }\end{array}$ & D $5 / 12$ \\
\hline 10 & 14 & $\begin{array}{l}\text { Acidosis, CCF, } \\
\text { ventilated, } \\
\text { inotropes }\end{array}$ & 14 & 3.9 & Moderate & - & $\mathrm{D}<24 \mathrm{hr}$ \\
\hline 11 & 2 & CCF, DO & 2 & 3.98 & Severe & - & A diur \\
\hline 12 & 2 & CCF & 52 & $3 \cdot 1$ & - & - & $A$ and $W$ \\
\hline
\end{tabular}

A diur, alive, CCF requiring diuretics; $A$ and $W$, alive and symptom free; AVSD, atrioventricular septal defect; CCF, congestive cardiac failure; Coarct, coarctation of the aorta; D, died $(-/ 12=$ months, $-152=$ weeks $)$; DO, ductus arteriosus open; $\mathrm{EFE}$, endocardial fibroelastosis; MR, mitral regurgitation; $\mathrm{P}$, on infusion of prostaglandin $\mathrm{E}$; VSD, ventricular septal defect.

gone balloon dilatation of the aortic valve and form the basis of this study. Two patients were not treated as they were considered to have hypoplastic left heart syndrome. Both had an aortic valve diameter of $<3 \mathrm{~mm}$, maximum left ventricular diameter of $<1 \cdot 3$ $\mathrm{cm}$ and very severe, contracted endocardial fibroelastosis.

Age at presentation to medical attention ranged from one to 42 days, weight from $3 \cdot 1$ to $4.6 \mathrm{~kg}$. Nine infants presented at $<1$ week of age, six of these within the first 3 days of life. Age at referral ranged from 1 to 52 days.

All infants had severe congestive cardiac failure and diminished or absent peripheral pulses. Nine infants were oliguric and four were moribund, requiring full inotropic and ventilatory support. Four infants were receiving infusions of prostaglandin $\mathrm{E}$.

ECHOCARDIOGRAPHIC ASSESSMENT

All infants were assessed by detailed cross sectional and Doppler echocardiography. The cardiac dimensions measured for each patient were: left ventricular diastolic diameter from the parasternal long axis (PLA) and apical four chamber (A4C) views, at the level of the papillary muscles; maximum left ventricular length from the A4C view, from apical endocardium to ventricular surface of the central fibrous body; aortic valve diameter from the parasternal long axis view, between the hinge points of the valve leaflets during systole; aortic root diameter from the parasternal long axis view, at maximum systolic diameter of the sinuses of Valsalva: mitral valve area was calculated from mitral valve diameters measured on the atrial surface of the hinge points from two orthogonal planes (parasternal long axis and $\mathrm{A} 4 \mathrm{C}$ views) with the formula for area of an ellipse: area $=\pi$ ((D) $\times \mathrm{D} 2) / 2$ ).

Maximum left ventricular diameter ranged from 1.5 to $2.64 \mathrm{~cm}$ and length from 1.75 to $4 \mathrm{~cm}$. Thus the group included both infants with dilated and with small left ventricles. Diameter of the left ventricle was sometimes greater when measured from the $\mathrm{A} 4 \mathrm{C}$ view than the more conventional parasternal long axis view. Diameter of the aortic valve

Table 2 Cardiac and balloon dimensions

\begin{tabular}{|c|c|c|c|c|c|c|c|}
\hline $\begin{array}{l}\text { Patient } \\
\text { No }\end{array}$ & $\begin{array}{l}L V \text { diameter } \\
(P L A(\mathrm{~cm}))\end{array}$ & $\begin{array}{l}L V \text { diameter } \\
(A 4 C(\mathrm{~cm}))\end{array}$ & $\begin{array}{l}\text { LV length } \\
(A 4 C(\mathrm{~cm}))\end{array}$ & $\begin{array}{l}M V \text { area } \\
\left(\mathrm{cm}^{2}\right)\end{array}$ & $\begin{array}{l}\text { Aorric annulus } \\
(P L A(m m))\end{array}$ & $\begin{array}{l}\text { Balloon } \\
\text { diameter }(\mathrm{mm})\end{array}$ & $\begin{array}{l}\text { Balloons** } \\
(n)\end{array}$ \\
\hline $\begin{array}{l}1 \\
2 \\
3 \\
4 \\
5 \\
6 \\
7 \\
8 \\
9 \\
10 \\
11 \\
12 \\
\text { Mean } \\
\text { (range) }\end{array}$ & $\begin{array}{l}2.55 \\
1.88 \\
2.4 \\
2.56 \\
1.53 \\
1.71 \\
2.57 \\
1.66 \\
1.75 \\
1.5 \\
2.1 \\
1.63 \\
1.99 \\
(1.5-2.57)\end{array}$ & $\begin{array}{l}2 \cdot 1 \\
1 \cdot 7 \\
1 \cdot 8 \\
2 \cdot 58 \\
1 \cdot 5 \\
1 \cdot 63 \\
2 \cdot 64 \\
1 \cdot 9 \\
1 \cdot 68 \\
- \\
2 \cdot 19 \\
2 \cdot 46 \\
2 \cdot 02 \\
(1 \cdot 5-2 \cdot 64)\end{array}$ & $\begin{array}{l}3 \cdot 4 \\
2 \cdot 77 \\
2 \cdot 8 \\
3 \cdot 87 \\
2 \cdot 07 \\
2 \cdot 95 \\
4 \\
2 \cdot 7 \\
2 \cdot 5 \\
1 \cdot 75 \\
3 \cdot 3 \\
3 \cdot 56 \\
2 \cdot 97 \\
(1 \cdot 75-4)\end{array}$ & $\begin{array}{l}2 \cdot 29 \\
1.90 \\
2.09 \\
2.45 \\
1.38 \\
1.45 \\
2.24 \\
2.02 \\
1.47 \\
2 \cdot 20 \\
1.55 \\
1.73 \\
1.90 \\
(1 \cdot 38-2 \cdot 45)\end{array}$ & $\begin{array}{l}7 \\
6 \cdot 5 \\
6 \cdot 5 \\
8 \\
6 \cdot 5 \\
7 \\
8 \\
5 \\
6 \\
6 \cdot 8 \\
5 \\
8 \\
6 \cdot 7 \\
(5-8)\end{array}$ & $\begin{array}{l}6 \\
5 \\
6 \\
6 \\
5 \\
5 \text { and } 7 \\
8 \\
3 \\
4 \text { and } 6 \\
3 \cdot 5 \text { and } 6 \\
6 \\
8 \\
6 \cdot 0^{*} \\
(3-8)\end{array}$ & $\begin{array}{l}2 \\
1 \\
1 \\
1 \\
1 \\
2 \\
1 \\
3 \\
2 \\
2 \\
2 \\
1 \\
1 \cdot 58 \\
(1-3)\end{array}$ \\
\hline
\end{tabular}

*Mean of maximum diameter balloon for each patient actually inflated across aortic valve.

$\star \star$ Number of balloons used including those not actually inflated across aortic valve.

A4C, apical four chamber view; MV area, mitral valve area calculated from MV diameters measured from A4C and PLA views; PLA, parasternal long axis view. 
Table 3 Aortic valve gradients

\begin{tabular}{|c|c|c|c|c|}
\hline $\begin{array}{l}\text { Patient } \\
\text { No }\end{array}$ & $\begin{array}{l}\text { Echo, before } \\
\text { dilatation } \\
\text { (mm Hg) }\end{array}$ & $\begin{array}{l}\text { Catheter, before } \\
\text { dilatation } \\
(\mathrm{mm} \mathrm{Hg})\end{array}$ & $\begin{array}{l}\text { Catheter, after } \\
\text { dilatation } \\
(\mathrm{mm} \mathrm{Hg})\end{array}$ & $\begin{array}{l}\text { Echo, } F U \\
\text { (or last) } \\
\text { (mm } \mathrm{Hg} \text { ) }\end{array}$ \\
\hline $\begin{array}{l}1 \\
2 \\
3 \\
4 \\
5 \\
6 \\
7 \\
8 \\
9 \\
10 \\
11 \\
12 \\
\text { Mean } \\
\text { (range) }\end{array}$ & $\begin{array}{c}36 \\
104 \\
35 \\
44 \\
29 \\
40 \\
64 \\
77 \\
43 \\
95 \\
47 \\
92 \\
58 \cdot 8 \\
(29-104)\end{array}$ & $\begin{array}{l}\overline{120} \\
70 \\
110 \\
- \\
89 \\
50 \\
- \\
75 \\
- \\
89 \\
110 \\
89 \cdot 1 \\
(50-120)\end{array}$ & $\begin{array}{l}\overline{70} \\
25 \\
60 \\
\frac{37}{13} \\
\overline{40} \\
\overline{40} \\
20 \\
38 \cdot 1 \\
(13-70)\end{array}$ & $\begin{array}{l}60 \\
(52) \\
36 \\
70 \\
(20) \\
(20) \\
50 \\
\frac{-}{(36)} \\
\frac{50}{31} \\
47 \cdot 5 \\
(20-100)\end{array}$ \\
\hline
\end{tabular}

ECHO, gradient measured by continuous wave Doppler echocardiography; ECHO, FU, Gradient measured at most recent follow up examination (or last examination before death).

was between 5 and $8 \mathrm{~mm}$, calculated mitral valve area was between 1.38 and $2.45 \mathrm{~cm}^{2}$ (table 2).

The aortic valve gradient was assessed with continuous wave Doppler echocardiography. The peak systolic flow velocity was measured and the valve gradient calculated with the modified Bernoulli equation. The pressure gradients across the aortic valve ranged from 29 to $104 \mathrm{~mm} \mathrm{Hg}$ (table 3). Other associated malformations and abnormalities were noted and their severity assessed. Six infants had significant associated abnormalities (table 1). Coarctation of the aorta was present in five and was severe at presentation in three. One infant had a complete atrioventricular septal defect, one had a small trabecular ventricular septal defect, and one had severe mitral regurgitation.

Endocardial fibroelastosis was noted and graded as follows: Mild, small patches or confined to the papillary muscles; moderate, diffuse patches but no large areas involved; severe, confluent over most of the endocardial surface. Nine infants had endocardial fibroelastosis. This was severe in four, moderate in three, and mild in two (table 1).

Patency of the arterial duct was noted in eight infants, four of whom were receiving infusions of prostaglandin $\mathrm{E}$.

Choice of treatment was based both on clinical and echocardiographic findings (tables 1-3). Aortic valve gradient was not the sole criterion for undertaking dilatation as the high incidence of ventricular dysfunction and

Figure 1 Right anterior oblique radiograph showing a $4 \mathrm{~mm}$ coronary angioplasty balloon inflated across the aortic valve, with the 0.014 inch guide wire looped within the left ventricle. coarctation renders this measurement an unreliable indicator of the severity of stenosis of the valve.

\section{TIMING OF PROCEDURE}

In one patient, severe coarctation was initially considered to be the principle lesion and this was treated surgically soon after admission (table 1). Therefore balloon dilatation was deferred, and was performed on the 55th day of life (49 days after repair of coarctation). In the rest of the patients, dilatation was performed within 36 hours of arrival at our unit, after stabilisation of the infant's condition where possible. One infant had presented with a systolic murmur at 2 days of age and had symptoms of cardiac failure from soon after birth. These were not recognised until review at 6 weeks of age, after which the patient was referred.

\section{DILATATION TECHNIQUE}

\section{Procedure}

All infants were anaesthetised, intubated, and ventilated for the procedure. They received antibiotic prophylaxis with $25 \mathrm{mg} / \mathrm{kg}$ of flucloxacillin and $3 \mathrm{mg} / \mathrm{kg}$ of netilmicin in accordance with our unit's policy for interventional catheter procedures. Prostaglandin infusion was maintained where previously instituted. The femoral artery approach was used. A cutdown was needed to allow access in one patient; in the rest a percutaneous approach was used. Heparin was given at a dose of 100 units $/ \mathrm{kg}$. Four or $5 \mathrm{~F}$ gauge catheters were used to place either a steerable coronary angioplasty or paediatric valvoplasty $(0.014$ inch to 0.020 inch diameter) guide wire or an 0.035 inch diameter (straight or J) guide wire across the aortic valve. Where possible, the wire was looped within the left ventricle in an attempt to avoid left ventricular perforation. The puncture site in the groin was dilated to 6 or 7F for direct percutaneous introduction of the balloon catheter over the wire without the use of a sheath. The balloon catheter was then passed over the guide wire and positioned across the aortic valve. Three or more rapid inflations and deflations of the balloon were performed with dilute contrast medium. The balloon position was adjusted so that the aortic valve was in the central portion of the balloon at full inflation. The left ventricular pressure was not always measured during the procedure, either due to difficulties crossing the valve with a catheter or to haemodynamic instability with a catheter blocking an undilated opening.

DETAIIS OF DILATATION BALLOON CATHETER Maximum balloon size was selected for each patient as equal to, or marginally less than, the aortic valve diameter measured echocardiographically (table 2). The balloon catheters used had diameters (inflated) of between 3 and $8 \mathrm{~mm}$. A total of 19 balloon catheters were used on 12 patients, with a maximum of three balloon catheters per patient. In four patients a balloon catheter of sub-maximal diameter was used initially to 
Figure 2 Right anterior oblique radiograph of the same patient as in fig 1 with a $6 \mathrm{~mm}$ balloon inflated across the valve on a 0.035 inch wire.

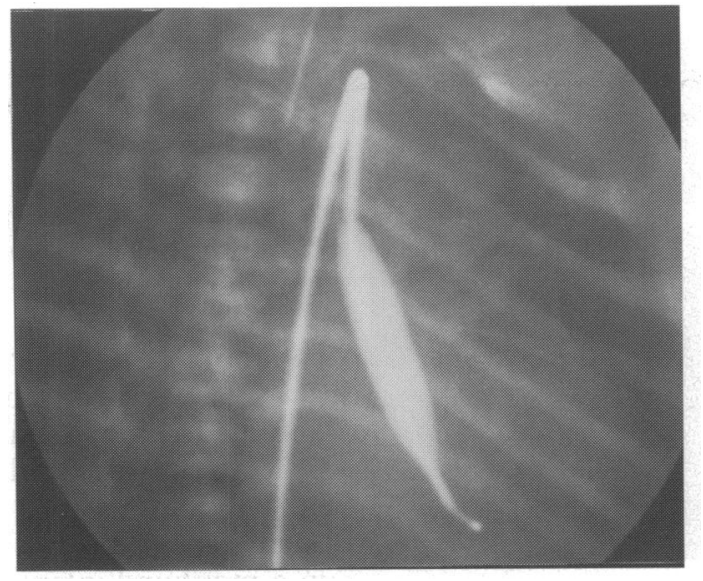

predilate a severely stenotic valve and permit subsequent passage of a larger balloon. In three of these, 3 to $4 \mathrm{~mm}$ ACS RX or Cordis Helix coronary angioplasty balloons (3.3 and $3.5 \mathrm{~F}$ shafts) were used, (fig 1 ); in the other, a $5 \mathrm{~mm}$ Meditech balloon catheter was used. This was followed in three by successful inflation of a larger balloon across the valve (fig 2) but in the patient with the smallest valve (patient 8), the coronary angioplasty balloon provided the final treatment as it was not possible to cross the valve with any larger balloon catheters. In patient 1 , two balloon catheters were used as the first balloon burst. In patient 11 , two balloon catheters the same size were needed due to difficulties of maintaining the position of the first (Tyshak Ghost, $6 \mathrm{~mm}$ on $4 \mathrm{~F}$ shaft). Eleven Meditech valvoplasty balloon catheters (diameters 5-8 $\mathrm{mm}$ on $5 \mathrm{~F}$ shafts) were used, along with two Schneider Monofoil (5 and $6 \mathrm{~mm}$ on $5 F$ shafts) and 2 Tyshak Ghost (6 and $8 \mathrm{~mm}$ on 4 and $5 \mathrm{~F}$ shafts) balloon catheters.

\section{TREATMENT OF COARCTATION}

Of the three patients with severe coarctation at presentation, one was treated by early surgery and delayed balloon dilatation. Both subsequent patients were treated by primary balloon dilatation of the native coarctation after the dilatation of the valve with the same balloon (figs 3 and 4). One child developed noticeable coarctation several months later

Figure 3 Right anterior oblique aortogram showing a discrete coarctation distal to the left subclavian artery after ductal closure, which was repaired surgically at 10 months of age. In another infant an echocardiographic diagnosis of mild coarctation not requiring early treatment was confirmed at necropsy.

\section{ANGIOGRAPHY}

Angiography was avoided unless absolutely necessary to cross the valve or delineate the site of a coarctation in an attempt to avoid the haemodynamic instability often produced by contrast medium in very sick infants. It was considered that the echocardiographic anatomical information was sufficient and that the potential benefits of additional angiographic details were outweighed by the risks of angiography.

\section{PROCEDURE TIMES}

Procedure times varied from 30 to 228 (mean $91.4)$ minutes, with time to arterial cannulation from 7 to 110 (mean 30.8 ) minutes. Screening times were between 9.6 and 101.5 (mean 40.4) minutes ( $<30$ minutes in four and $>1$ hour in two patients).

\section{Results}

SHORT-TERM OUTCOME (< ONE MONTH AFTER DILATATION)

Of the 12 infants treated, two gained no apparent haemodynamic benefit from the procedure. They were in a parlous state at presentation and died soon afterwards. Symptoms were improved by dilatation in 10 patients $(83 \%)$. A third patient died within the first month after dilatation; therefore early survival was $75 \%$. Catheter gradients (where measured) fell in all patients after dilatation. Echocardiographic gradients often seemed to increase as ventricular function improved.

Postmortem examination of the infants who died soon after dilatation (patients 8 and 10), confirmed adequate relief of the stenosis of the valve but considerable left ventricular hypoplasia in both cases. In patient 10 there was also a $3 \mathrm{~mm}$ perforation of the left coronary cusp of a very dysplastic valve. Patient 6 responded well to dilatation of the aortic valve initially, but then his mitral regurgitation worsened. This proved refractory to treatment leading to death at two weeks of age. Necropsy showed no evidence of mitral valve trauma and suggested that the mitral regurgitation was related to papillary muscle dysfunction and endocardial fibroelastosis. Figure 5 shows the adequacy of relief of commissural fusion achieved in this and other patients despite considerable dysplasia of the valve.

\section{MEDIUM-TERM OUTCOME ( $>$ ONE MONTH} AFTER DILATATION)

Of the nine patients surviving $>1$ month after dilatation, three more have died; thus six $(50 \%)$ currently survive and have been followed up for up to 39 months.

Patient 5, with an atrioventricular septal defect, initially improved after dilatation. There was, however, persistent heart failure 
Figure 4 Right anterior same patient as in fig 3 , showing reduction of narrowing after balloon dilatation. oblique aortogram of the

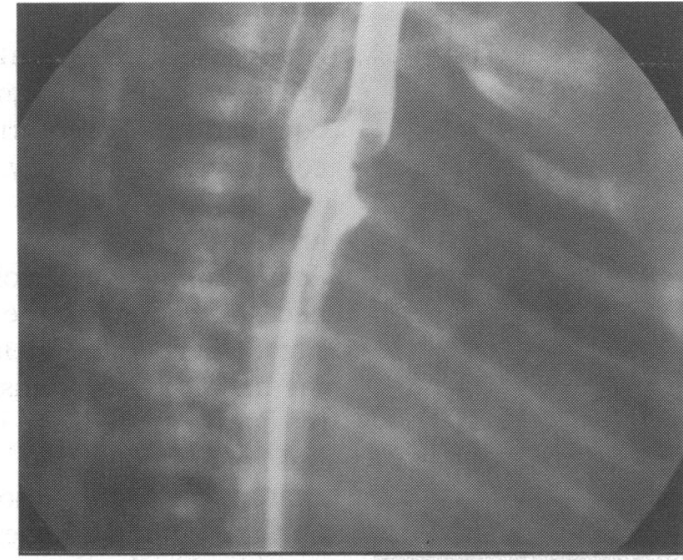

with considerable left ventricular hypoplasia and she died aged 2 months during a febrile illness. The additional mild coarctation was confirmed at necropsy. Patient 2, who developed coarctation late, had required a second dilatation of the aortic valve at 8 months. He had very severe endocardial fibroelastosis with persistent left ventricular dysfunction and heart failure. This was exacerbated by operative repair of coarctation and led to his death at 10 months of age. Patient 6, with Turner's syndrome, aortic stenosis, and severe coarctation made good early progress, but died aged five months after an acute bronchiolitic illness with recurrent heart failure. Necropsy showed recurrent coarctation that was likely to have contributed to the death.

All survivors are followed up with regular echocardiographic examinations; residual aortic valve gradients range between 20 and $70 \mathrm{~mm} \mathrm{Hg}$ at last follow up (table 3). Three patients have required repeat dilatations so far, at 8 months in patient 2 , at 5 and 17 months in patient 4. Patient 11 recently underwent successful repeat dilatation and continuing diuretic treatment is unlikely to be

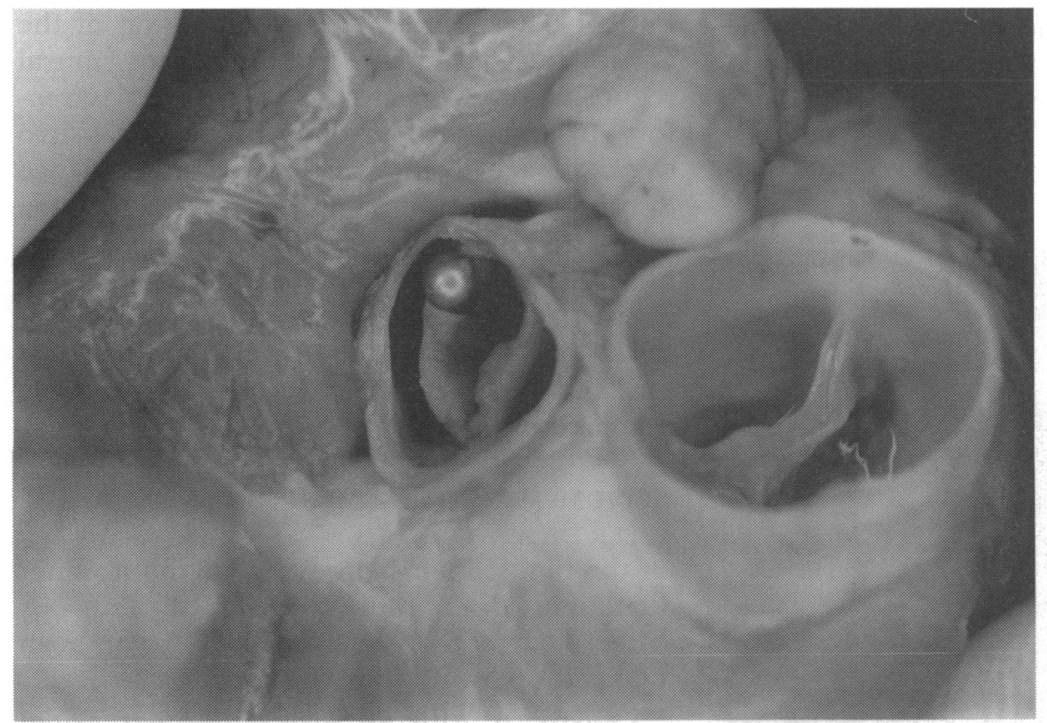

Figure 5 Postmorten specimen from patient 6, showing the disparity in size between the aortic and pulmonary valves. The aortic valve is bicuspid and dysplastic but there is no evidence of residual commissural fusion when the valve cusps are separated with a probe. necessary. Patient 3 still requires diuretics, with severe endocardial fibroelastosis and ventricular dysfunction but minimal stenosis of the valve.

Echocardiography also shows mild aortic regurgitation in five patients none of whom currently have an audible aortic regurgitant murmur.

\section{PROCEDURAL COMPLICATIONS}

Two infants died from persistent low cardiac output despite adequate dilatation and have been discussed earlier. Cusp perforation occurred in patient 10 despite the use of angiography; this was a protracted procedure in a moribund infant, with multiple attempts at crossing the valve before 3.5 and $6 \mathrm{~mm}$ balloons were eventually inflated across it. Death was probably not due to the cusp perforation, but, had the patient survived, aortic regurgitation might well have been a major problem. Cardiac tamponade occurred in one infant after perforation of the left ventricle by the guide wire. This was successfully treated by prompt pericardial aspiration. Balloon rupture occurred during the first procedure but caused no complications. One infant developed transient symptom free left bundle branch block at full inflation of the balloon, which resolved within 10 minutes. At most recent examination (including those that subsequently died), four infants were noted to have a reduced or absent pulse of the femoral artery on the cannulated side, but none have had other evidence of ischaemia of the limb.

\section{FACTORS INFLUENCING OUTCOME}

\section{(a) Ventricular size}

Maximum left ventricular diameter, measured from either the PLA or the A4C view, was compared between those infants who died and those who have survived. The difference between the groups was highly significant (Students $t$ test, $\mathrm{p}<0.001$ ). Figure 6 shows that there was no overlap between the two groups, all the infants who died had maximum left ventricular diameters of $1.9 \mathrm{~cm}$ or less. The child who died latest, at 10 months of age, had the largest diameter of that group. The left ventricular length was also signifi-

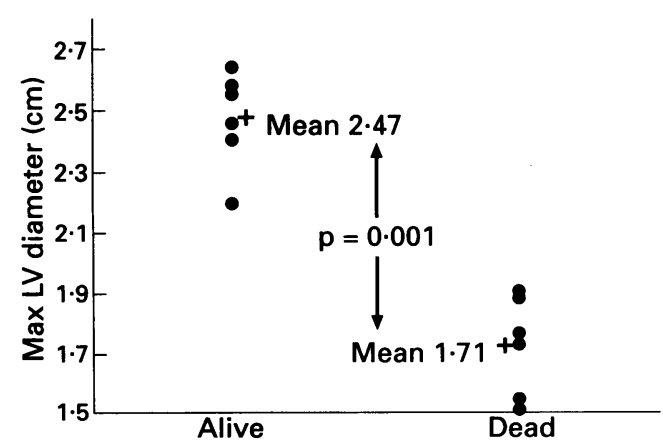

Figure 6 Survival in relation to maximum left ventricular diameter measured echocardiographically from either the parasternal long axis or apical four chamber view. (Students $t$ test). 
cantly shorter $(p=0.002)$ in those that died $(1 \cdot 75-2.95$ (mean $2 \cdot 46) \mathrm{cm}$ ) than in survivors $(2 \cdot 8-4 \cdot 0(3 \cdot 45) \mathrm{cm})$.

\section{(b) Aortic valve and root diameters}

There were no significant differences in aortic valve or root diameters between those infants who died and those who survived.

\section{(c) Associated malformations}

Of the six infants with associated cardiac malformations, only one survives. Five out of the six deaths in this study were in patients with additional malformations.

\section{(d) Endocardial fibroelastosis}

All four patients with severe endocardial fibroelastosis derived benefit from balloon dilatation of the aortic valve and survived the neonatal period, although patient 2 died aged 10 months. Two patients with moderate and one with mild endocardial fibroelastosis also died.

\section{(e) Age and condition at presentation}

Of the six infants presenting in the first three days of life, three died, but all more than one month after dilatation. Of the six infants presenting four or more days after birth, three died, two very soon after dilatation. Only one of the four infants who were inotrope and ventilator dependent before dilatation still survives. Of the eight patients (four treated with prostaglandins) in whom the ductus arteriosus was patent at presentation, five (three treated with prostaglandins) have subsequently died. Only two of these deaths, however, occurred very early after dilatation and were possibly attributable to inability of the left ventricle to support the systemic circulation.

\section{Discussion}

This study shows encouraging results for a policy of balloon dilatation as the primary treatment for patients with severe symptomatic aortic stenosis presenting in the first two months of life. The group studied is a high risk one, including a number of patients with considerable left ventricular hypoplasia and a high incidence of associated malformations and endocardial fibroelastosis; all factors known to be associated with a high mortality in other series. Zeevi et al compared results for surgery and dilatation of the valve within a single centre and found that both techniques seemed equally effective. ${ }^{12} \mathrm{~A}$ more recent report from the same centre confirmed that any differences in survival could be explained on the basis of patient selection. ${ }^{13}$ Ideally, a controlled trial of balloon dilatation of the aortic valve $v$ surgery is needed. With the small numbers of eligible patients presenting each year, however, this would require a large multicentre trial. This could pose considerable organisational problems and interpretation of results would be difficult.

PATIENT GROUP

Knowledge of the pattern of patients accrued is important for comparison of results between centres and between treatments. In three years, 14 infants with severe symptomatic stenosis of the aortic valve reached our unit alive. Two were not offered treatment as they clearly had hypoplastic left heart syndrome with stenosis of the aortic valve rather than complete atresia. Twelve underwent balloon dilatation. Balaji et al from Southampton reported that nine infants in 13 years received operations for aortic stenosis aged $<6$ weeks (two of these were symptom free). ${ }^{7}$ Burch et al reported the results of 13 operations for infants ( $<1$ year of age) with aortic stenosis over a five year period. ${ }^{8} \mathrm{Wren}$ et al treated seven patients aged $<6$ weeks with balloon dilatation of the aortic valve in two years. ${ }^{10}$ Thus by standards in the United Kingdom ours is a large series collected over a short time. This wide variation in numbers between different centres suggests that selection bias may also be different. It is likely to depend on referral and acceptance patterns as well as on criteria considered suitable for operation or classification as hypoplastic left heart syndrome rather than aortic stenosis. Alternatively, it might be that there is a particularly high incidence of this condition in the South West Region. The patient mix and incidence, however, is similar to the "unbiased" natural history study from the Liverpool area. ${ }^{1}$

The lack of preselection in our group is shown by its composition, with most patients at particularly high risk compared with those in several other studies. ${ }^{78}$ All infants had considerable congestive cardiac failure, most having developed symptoms within the first week of life. Four were moribund on arrival. Although six (plus the two with hypoplastic left heart syndrome) had other anomalies and nine had endocardial fibroelastosis none had been diagnosed antenatally. Gradients across the aortic valve measured by Doppler echocardiography seemed low $(<50 \mathrm{~mm} \mathrm{Hg}$ ) in seven patients. This may reflect to the presence of left ventricular dysfunction, or the difficulty of interpreting pressure gradients when multiple obstructive lesions (for example, coarctation plus aortic stenosis), or right to left ductal shunts are present.

RESULTS AND MEDIUM TERM SURVIVAL

Valvoplasty was achieved in all cases (that is, a balloon was inflated across the aortic valve). This is an improvement on earlier experiences, ${ }^{1011}$ and probably reflects the improvements in guide wire and balloon catheter design for paediatric use in recent years.

Early mortality was $27 \%$. Both deaths that occurred within 24 hours of dilatation related to a terminal clinical condition at the time of emergency dilatation, with considerable left ventricular hypoplasia. It is unlikely that either patient would have survived a surgical procedure. Use of the carotid ${ }^{14}$ or umbilical ${ }^{9}$ arterial approach might have reduced some rather protracted arterial access and screening times. Continuing improvements in equipment design can only benefit this procedure. 
Although our numbers are small, it seems that among infants presenting at $<2$ months of age, presentation within the first few days of life does not pose any additional risk. Indeed, some of those infants presenting later may actually have been in worse clinical condition. Although five of the deaths occurred in patients presenting with a patent arterial duct (three on infusions of prostaglandin $\mathrm{E}$ ), only two of these deaths probably resulted from left ventricular hypoplasia, the rest related principally to associated lesions. Ductal patency and the use of an infusion of prostaglandin were not a reliable guide to the ability of the left ventricle to support the systemic circulation.

Mid-term survival is $50 \%$. All four later deaths ( 2 weeks, 2,5 , and 10 months) were largely or wholly related to associated lesions. In total, five of the six patients with other malformations died. The difference in prognosis for survival with left ventricular diameter $>$ or $<1.9 \mathrm{~cm}$ is striking but consistent with other studies. ${ }^{15}$ The differences in left ventricular length are also notable, although there is a degree of overlap between groups. The predictive scoring system proposed by Rhodes and coworkers ${ }^{15}$ could not be usefully applied to this study population because of the high incidence of associated malformations and severe endocardial fibroelastosis. None of the four patients with adequate left ventricular dimensions and otherwise normal cardiac anatomy died, despite all four having moderate or severe endocardial fibroelastosis. This contrasts with the Guy's hospital experience of a $100 \%$ mortality for their neonates with severe endocardial fibroelastosis. ${ }^{16}$ Many of their patients, and none of ours, were diagnosed antenatally, again showing the difficulties inherent in comparing results between different populations of patients. Aortic regurgitation has not been a problem so far in our series, although the patient with a perforated cusp would have had important regurgitation had she survived.

\section{LONG-TERM OUTLOOK}

Myocardial function must remain a concern. Four of the survivors have moderate or severe endocardial fibroelastosis and another has treated coarctation. Endocardial fibroelastosis was not a clear risk factor for early death in our series, but obviously it may continue to aфversely affect long-term prognosis and functional state. Repeat dilatation procedures have been and will be required but this is neither unexpected nor unacceptable. Repeat balloon dilatation is likely to carry considerably less risks than repeat surgical valvotomy or aortic valve or root replacement in early childhood, particularly where there is myocardial dysfunction. It offers the attraction of deferring definitive surgery and preserving the surgical field, as most patients will require multiple surgical procedures in later life. So far we have had no important clinical problems from arterial occlusion, although repeated dilatations may make this more likely.

\section{THE FUTURE?}

In their analysis of differential survival after surgical valvotomy or balloon dilatation, Lopez et al noted that the survival rate of high risk infants was not improved by the use of balloon dilatation. ${ }^{13}$ These patients, with low birthweight, left ventricular hypoplasia, or additional cardiac malformations, ${ }^{15}$ might have been expected to be the ones to benefit most from a less invasive procedure. Closer examination of this is indicated. Prompt treatment of associated lesions is vital. One neonate from our series survived for five months despite a left ventricular diameter $<1.9 \mathrm{~cm}$, severe coarctation, and Turner's syndrome. The presence of a dysmorphic syndrome may have led to more rapid recognition of symptoms and referral than usual, so that balloon dilatation of the aortic valve and the coarctation were performed on day 2 of life. Despite requiring inotropic support early after dilatation, she then made good progress until congestive cardiac failure recurred due to recoarctation. Aortic coarctation and severe stenosis of the aortic valve commonly occur together. Combining surgical treatment of coarctation and aortic valvotomy in a single procedure is feasible but not widely reported and there are no comparative reports with balloon dilatation. Balloon dilatation of native coarctation in newborn patients has a high incidence of early recoarctation, ${ }^{17}$ and early repeat dilatation or surgery for recoarctation may be required. A combination of surgical and interventional catheter management might be possible here. Infants with very small ventricles may well require a different approach, perhaps along the same lines as for those with the hypoplastic left heart syndrome.

1 Kitchener DJ, Jackson M, Walsh K, Peart I, Arnold R. The incidence and prognosis of congenital aortic valve The incidence and prognosis of congenital aortic valve 69:71-9.

2 Lababidi $\dot{Z}$, Wu J, Walls JT. Percutaneous balloon aortic valvuloplasty: results in 23 patients. $A m f$ Cardio 1984;53:194-7.

3 Choy M, Beekman RH, Rocchini, AP, et al. Percutaneous balloon valvuloplasty for valvar aortic stenosis in infants and children. Am $\mathcal{F}$ Cardiol 1987;59:1010-3

4 Rocchini AP, Beekman RH, Ben Shachar G, et al. Balloon aortic valvuloplasty: results of the valvuloplasty and angioplasty of congenital anomalies registry. $\mathrm{Am} \mathscr{F}$ Cardiol 1990;65:784-9.

5 Pelech AN, Dyck JD, Trusler GA, et al. Critical aortic stenosis, survival and management. $\mathcal{F}$ Thorac Cardiovasc Surg 1987;94:510-7.

6 Hammon JW, Lupinetti FM, Maples MD, et al. Predictors of operative mortality in critical valvular aortic stenosis presenting in infancy. Ann Thorac Surg 1988;45:537-40.

7 Balaji S, Keeton BR, Sutherland GR, Shore DF, Monro IL. Aortic valvotomy for critical aortic stenosis in IL. Aortic valvotomy for critical aortic stenosis in 1989;61:358-60.

8 Burch M, Redington AN, Carvalho JS, et al. Open valvotomy for critical aortic stenosis in infancy. Br Heart $\mathcal{f}$ tomy for critical

9 Beekman RH, Rocchini AP, Amy Andes RN. Balloon valvuloplasty for critical aortic stenosis in the newborn Influence of the new catheter technology. $\mathrm{F} \mathrm{Am}$ Coll Cardiol 1991;17:1172-6.

10 Wren C, Sullivan I, Bull C, Deanfield J. Percutaneous balloon dilatation of aortic valve stenosis in neonates and infants. $\mathrm{Br}$ Heart $\mathcal{f} 1987 ; 58: 608-12$.

11 Kasten-Sportes CH, Piechaud JF, Sidi D, Kachaner J. Percutaneous balloon valvuloplasty in neonates with critical aortic stenosis. $\mathcal{F}$ Am Coll Cardiol 1989;13: 1101-5

12 Zeevi B, Keane JF, Casteneda AR, Perry SB, Lock JE Neonatal critical valvar aortic stenosis: a comparison of surgical and balloon dilation therapy. Circulation 1989 80:831-9. 
13 Lopez L, Colan SD, Rhodes LA, et al. Differential survival after surgical or balloon valvotomy for critical survival after surgical or balloon valvotomy for critical 1992;25A:705.

14 Fischer DR, Ettedgui JA, Park SC, Siewers RD, Del Nido PJ. Carotid artery approach for balloon dilation of aortic valve stenosis in the neonate: a preliminary report. $\mathcal{f ~} \mathrm{Am}$ Coll Cardiol 1990;15:1633-6.

15 Rhodes LA, Colan SD, Perry SB, Jonas RA, Sanders SP.
Predictors of survival in neonates with critical aortic stenosis. Circulation 1991;84:2325-35.

16 Ladusans EJ, Parsons JM, Qureshi SA, Baker EJ, Tynan

MJ. Results of percutaneous balloon dilatation for critical aortic stenosis in neonates with severe endocardial fibroelastosis [abstract]. Br Heart $\mathcal{f}$ 1989;61:470.

17 Redington AN, Booth P, Shore D, Rigby ML. Primary balloon dilatation of coarctation of the aorta in neonates. Br Heart $\mathcal{f}$ 1990;64:277-81.

\title{
SHORT CASES IN CARDIOLOGY
}

\section{Recurrence of Churg Strauss vasculitis in a transplanted heart}

\author{
R A Henderson, P Hasleton, B N A Hamid
}

Departments of

Cardiology and

Pathology, Regional

Cardiothoracic

Centre, Wythenshawe

Hospital, Manchester

R A Henderson

P Hasleton

Department of

Pathology, Trafford

General Hospital,

Manchester

B N A Hamid

Correspondence to:

Dr R A Henderson,

Department of Cardiology,

Wythenshawe Hospital,

Wythenshawe Hos

Manchester M23 9LT.

Accepted for publication

17 September 1993.

Epicardial artery from donor heart showing a vasculitis with fibrinoid necrosis and a giant cell (arrow) (haematoxylin and eosin; original magnification, $\times 95$ ).
In October 1987 a 22 year old man with Churg Strauss syndrome and cardiac failure underwent orthotopic cardiac transplantation. ${ }^{1}$ Postoperatively he had recurrent attacks of asthma associated with eosinophilia, but there were no other features of Churg Strauss syndrome. Routine endomyocardial biopsy specimens showed no rejection or vasculitis until March 1991 when an episode of moderate myocardial rejection was treated with immunosuppressive therapy. In January 1992 cardiac catheterisation showed moderate impairment of left ventricular function and diffuse left coronary artery disease but the right coronary artery was angiographically normal. In March 1992 he suddenly collapsed with electromechanical dissociation and despite prolonged resuscitative efforts he died one hour later.

At necropsy there was severe pulmonary oedema and the heart was enlarged $(486 \mathrm{~g})$. Histological examination of the donor myocardium showed foci of myocardial fibrosis with patchy areas of rejection and myocyte damage. There was vasculitis in the intramyocardial and epicardial arteries. In the right coronary artery there was fibrinoid necrosis in the adventitia and necrosis of the vessel wall, with chronic inflammation containing lymphocytes, plasma cells, and a few eosinophils (figure). The proximal right coronary artery was occluded with thrombus. A postmortem diagnosis of Churg Strauss vasculitis was made.

Cardiac transplantation in patients with a systemic disease is controversial, because non-cardiac manifestations of the disease may influence prognosis and the disease may affect the donor heart. This case suggests that Churg Strauss syndrome is a relative contraindication to cardiac transplantation because vasculitis may recur in the transplanted heart.

1 Thomson D, Chamsi-Pasha H, Hasleton P. Heart transplantation for Churg-Strauss syndrome. Br Heart $\mathcal{f}$ 1989;62:409-10.

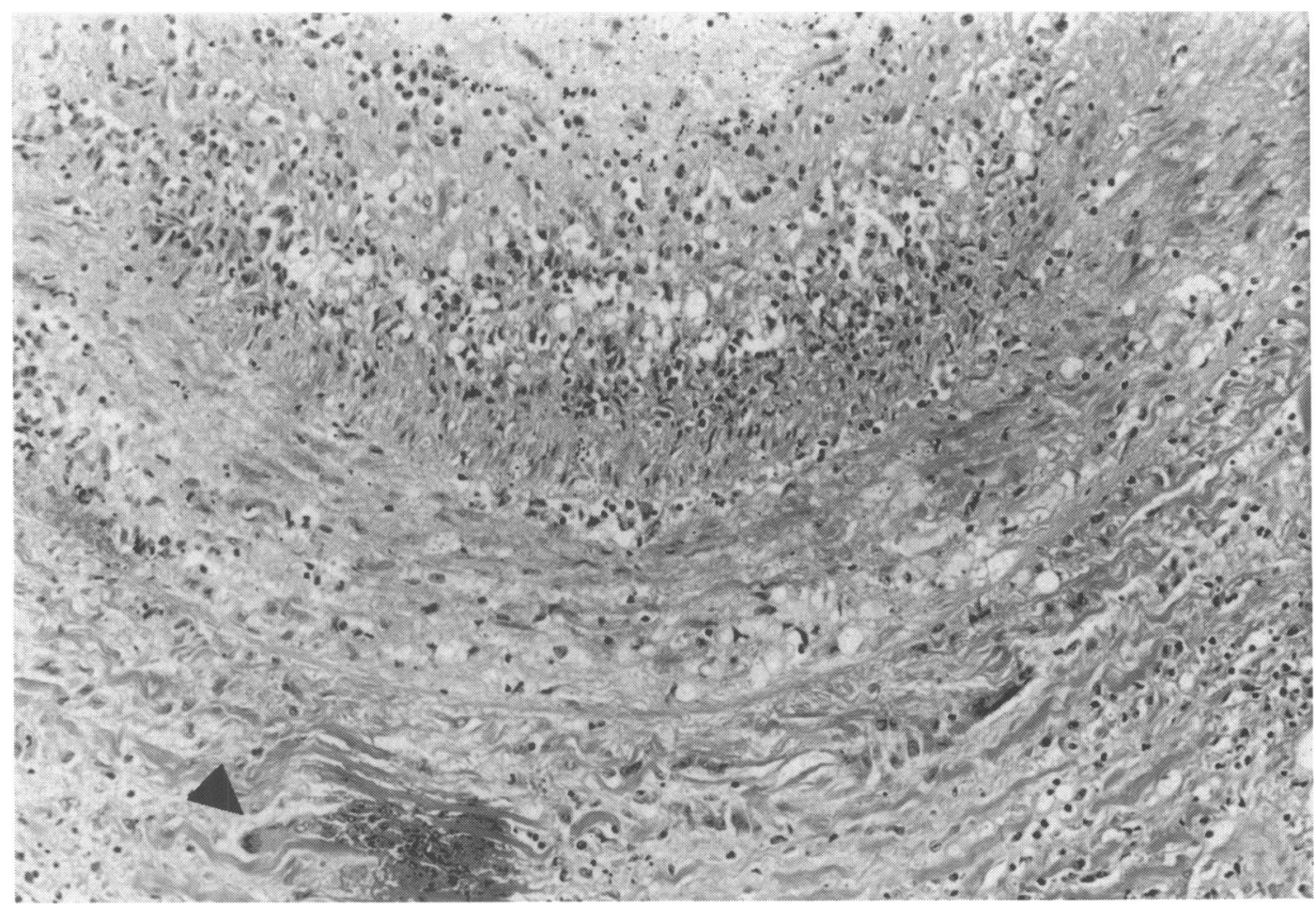

